\title{
USE OF REMOTELY PILOTED AERIAL SYSTEMS (R.P.A.S.) FOR WILDLIFE MONITORING
}

\author{
Veronica Racanelli, Sara Bartolozzi, Emanuele Sorbetti Guerri, Francesco Sorbetti Guerri \\ University of Florence, Italy \\ francesco.sorbettiguerri@unifi.it
}

\begin{abstract}
There are many methods to estimate wild ungulate populations. One of these is represented by observations from vantage points usually employed in medium-low covered forest areas to estimate cervids. This method is subject to some limitations, such as the risk of double counting and the necessity to a high number of operators due to the small size of the observable areas. Such limitations could be reduced by integrating the "vantage points method" with Remote Piloted Aircraft System (R.P.A.S.) surveys. This study reports some experiences carried out mainly to check the suitability of R.P.A.S. use in the specific case of Roe deer (Capreolus capreolus) and Wild boar (Sus scrofa). The investigation was conducted in various areas with a high density of Roe deer and in the absence of disturbing elements. The first experimental phase concerned the definition of technical parameters useful to characterize the research system. For this purpose, the acoustic emission of the aircraft $(\mathrm{dB})$ and shots of the underlying ground were recorded at intervals of $10 \mathrm{~m}$ up to $70 \mathrm{~m}$ above the ground. In the second phase, operating flights were carried out on an area of around $90,000 \mathrm{~m}^{2}$ consisting of seven contiguous grazing areas separated by hedges and woody plants. The ability to fly over the natural visual barriers (land orography, trees, hedges, etc.) allowed to conduct a census over all the study area, despite its size and its characteristics. Only two operators can do all the flights in an average time of about 10-15 minutes with a R.P.A.S. speed of approximately $3 \mathrm{~m} \cdot \mathrm{s}^{-1}$. The analysis of the aerial pics taken at dusk from 50 to 60 meters has identified many Roe deer grazing in different areas and has verified the absence of any animal alarm reactions to the passage of the aircraft. As for Wild boar, animal species with more pronounced nocturnal activity, the tests were conducted using a thermal imaging camera installed on board the R.P.A.S.
\end{abstract}

Keywords: monitoring, R.P.A.S., red deer, wild boar.

\section{Introduction}

In the last fifty years, the structure of the Italian rural territory went through significant modifications due to radical socio-economic change. Several wild species were strongly affected by the transformations of the agricultural and forest ecosystems and many large mammal populations, both herbivores and carnivores, recolonized the abandoned agricultural lands. Restocking plans implemented without proper management techniques, the abandonment of marginal areas as well as the spread of forest ecosystems have encouraged the increase of some wild species including wild ungulates [1]. This phenomenon has led to significant problems of cohabitation between wild fauna and human activities. In Tuscany, between 2000 and 2009, the estimated increase of wild ungulates populations was around $51 \%$ [2]. Wild boar and Cervids have a leading role in serious damages to agricultural productions, particularly to field crops, orchards and vineyards. For a proper management of the abovementioned species, the use of modern and rational instruments, such as Remotely Piloted Aircraft Systems (R.P.A.S. from now on), appears necessary [3; 4].

A first experimental approach was finalized to verify R.P.A.S. capability to improve the accuracy of the conventional methodologies for the estimation of Roe deer (Capreolus capreolus) and Wild boar (Sus scrofa) populations. The purpose of this study is to highlight specificities, opportunities and limits of R.P.A.S. through the results of some preliminary testing. More detailed tests were conducted thereafter to adjust contingent negative factors. Observations from vantage points are usually employed in medium-low coverage forest areas as a means to estimate wild ungulates populations [5]. This method can provide useful information, however it is affected by to some limitations as the risk of double counts and the high number of workforce needed: in fact, many operators are often allocated to control small areas. Furthermore, the high level of heterogeneity in skills, age and ability in the whole workforce can lead to a certain degree of unreliability of the collected data. Some of these limitations can be reduced by integrating visual observations with data obtained from images and videos taken by R.P.A.S. equipped with different types of devices such as RGB cameras, thermal cameras or multispectral sensors [6].

In 2016, the Laboratory of Applied Engineering to Wildlife (WildlifE-Lab) was established at the Department of Agricultural, Food and Forestry Systems of the University of Florence, in order to study wild animal populations with the aid of innovative methodologies. 
The first studies carried out by the WildlifE-Lab concerned the following themes:

- the possibility to identify animals in open areas from images or videos taken by R.P.A.S. at different flight altitude, in relation to the type of recording device, the flying altitude and the type of vegetation cover;

- the possible disturb caused to animals by the noise emitted from the rotors of the aircraft in relation to flight altitude;

- the extension of the analysed surface area at dusk (the most suitable time for wildlife detection using an RGB camera);

- the possibility to use thermal camera equipped with R.P.A.S. for night surveys.

\section{Materials and methods}

The tests were carried out_in the Province of Florence, Italy, from September 2016 to September 2017in different sessions. The four areas covered by the study were characterized by high Roe deer and Wild boar densities. Two different aircrafts were used for the experimental tests: a commercial quadcopter (Yuneek Q500+)(Fig. 1) equipped with a3-Axis CG02 GB gimbal camera (angle of view $155^{\circ}, 16$ millions of effective pixels) and a custom six-engine multicopter equipped with a Flir Tau2 336 radiometric thermal camera(Thermal Capture module,13mm lens, f/1.25 slow) (Fig. 2).

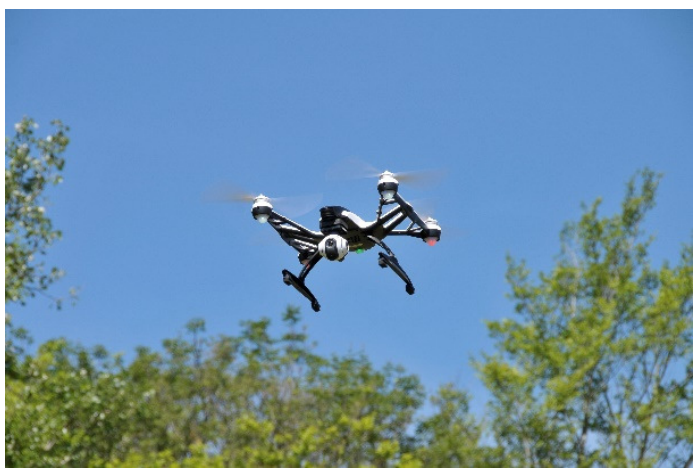

Fig. 1. R.P.A.S. Yuneek Q500+

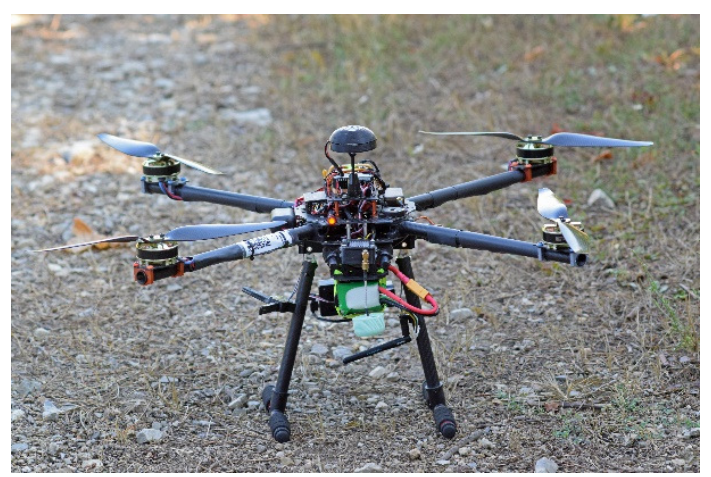

Fig. 2. Custom six-engine R.P.A.S.

The first experimental phase concerned the definition of the technical parameters useful to characterize the research system.

For this purpose, the acoustic emission of the aircraft $(\mathrm{dB})$ and photographs of the underlying area were recorded at intervals of 10 meters up to 70 meters above the ground.

The sound intensity levels of RPAS noise were taken from the ground using a Bruel \& Kjaer 2236 type 1 IEC sound level meter, specifically designed for environmental and occupational noise measurement (measuring range 34-110 dB). Every 10 meters of increase in the flight height, three sound intensity values were detected. Thereafter, these values were summarized using arithmetic mean.

The images of the underlying areas were analysed using Q-Gis, an open source GIS desktop application.

With increasing the flight altitude, the image details are reduced as well as the possibility of discriminating the presence of animals on the ground; conversely, at lower altitude the perception of the aircraft noise at the ground is increased.

The first tests are aimed at determining a trade-off in altitude between the lowest acoustic emission and best discrimination of the animals on the ground. However, shooting parameters can be appropriately adapted to different needs by choosing the most suitable filming device. Thereafter, several operating flights were conducted by night, day and dusk, over the different experimental areas.

In this paper we describe the surveys conducted in the Villa di Pratolino Park, on an area of $90.000 \mathrm{~m}^{2}$ characterized by 7 contiguous parcels separated by hedges and groves, summarized below, (Fig. 3). 


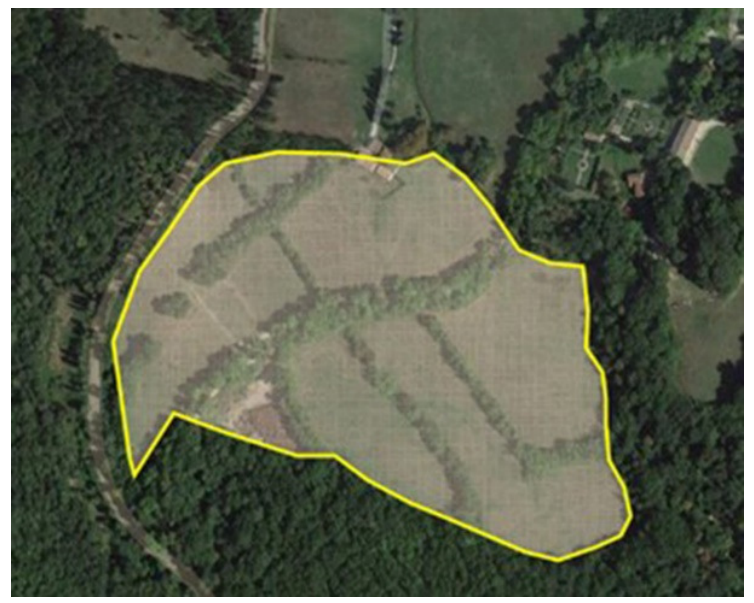

Fig. 3. Study area of Villa di Pratolino Park

The flights were made at sunset, according to the usual Cervids census practices from vantage points. The survey was carried out using the abovementioned RGB camera, flying at a height varying between 40 and 60 meters at a speed of about $3 \mathrm{~m} \cdot \mathrm{s}^{-1}$. Each flight lasted about 10-15 minutes, needed to fly over the entire area.

Regarding the species with more pronounced nocturnal mobility, such as the Wild boar, tests were conducted with a thermal imaging camera installed on R.P.A.S. in order to verify the ability of the instrument to discriminate the presence of wildlife by detecting temperature difference between the animals and the ground [7]. For this purpose, as previously mentioned, we used a custom aircraft characterized by autonomous flight and waypoints loaded by software and specially adapted with a Gimbal support designed to carry the thermal camera Flir Tau2 336 weighing 95 gr., (Fig. 4).

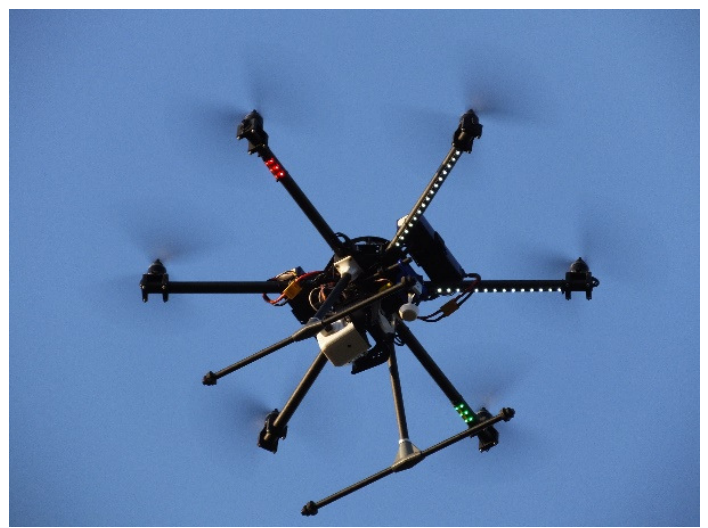

\section{Fig. 4. Six-engine custom R.P.A.S. with thermal camera}

The experimental flights were carried out in four sessions, from July to September 2017, in different conditions, with particular reference to ground temperature. The shots were taken in the early night hours after sunset, i.e. the periods of the night with higher temperatures on the ground, in order to assess the ability of the tool to discriminate the body of animals from the background in the most critical situation.

\section{Results and discussion}

The data recorded in the first experimental phase defined the technical parameters of the R.P.A.S. Yuneec Q500+.With the increase of the flight height, no considerable differences in the sound level atthe ground were detected, (Table 1).

Moreover, the surface area increases on average about $2000 \mathrm{~m}^{2}$ every $10 \mathrm{~m}$ increase in the flight altitude: at $50 \mathrm{~m}$ the surface area is about $7000 \mathrm{~m}^{2}$ with an acoustic pressure on the ground of $48.6 \mathrm{~dB}$, while at $40 \mathrm{~m}$ the surface is about $4000 \mathrm{~m}^{2}$ with an acoustic pressure of $52 \mathrm{~dB}$, (Fig. 5).

Despite the short flight autonomy of the R.P.A.S. per battery, it was possible to inspect large areas in detail, regardless of the presence of natural barriers (trees, hedges, terrain orography, etc.) even 
during the most suitable time for Roe deer mobility, in comparison to the surveys carried out from the ground. Therefore, even with a not particularly performant camera, it is possible to detect the presence of grazing Roe deer almost in complete darkness, also because the images can then be edited with a graphic processing software to enhance the image quality. The possibility to cover significantly wide surfaces allows to reduce the number of operators, to just the pilot and an assistant or observer, (Fig. 6).

Table 1

Measurement of R.P.A.S. noise intensity level $\left(\mathrm{dB}_{\mathrm{SPL}}\right)$

\begin{tabular}{|c|c|c|c|c|c|}
\hline Height, $\mathbf{m}$ & $\mathbf{1}^{\text {st }}$ trial & $\mathbf{2}^{\text {nd }}$ trial & $\mathbf{3}^{\text {th }}$ trial & $\mathbf{4}^{\text {th }}$ trial & Mean \\
\hline 0 & 60.0 & 58.3 & 56.0 & 57.0 & 57.8 \\
\hline 10 & 62.0 & 62.9 & 62.5 & 63.0 & 62.6 \\
\hline 20 & 59.5 & 57.5 & 56.5 & 60.0 & 58.4 \\
\hline 30 & 52.0 & 50.9 & 53.0 & 56.0 & 53.0 \\
\hline 40 & 50.0 & 50.5 & 51.5 & 56.0 & 52.0 \\
\hline 50 & 48.5 & 48.0 & 47.5 & 50.3 & 48.6 \\
\hline 60 & 47.0 & 47.5 & 49.5 & 47.5 & 47.9 \\
\hline 70 & 44.0 & 45.5 & 43.5 & 46.0 & 44.8 \\
\hline
\end{tabular}

RELIEF OF SURFACE BREADTH WITH RPAS $\left(\mathrm{m}^{2}\right)$

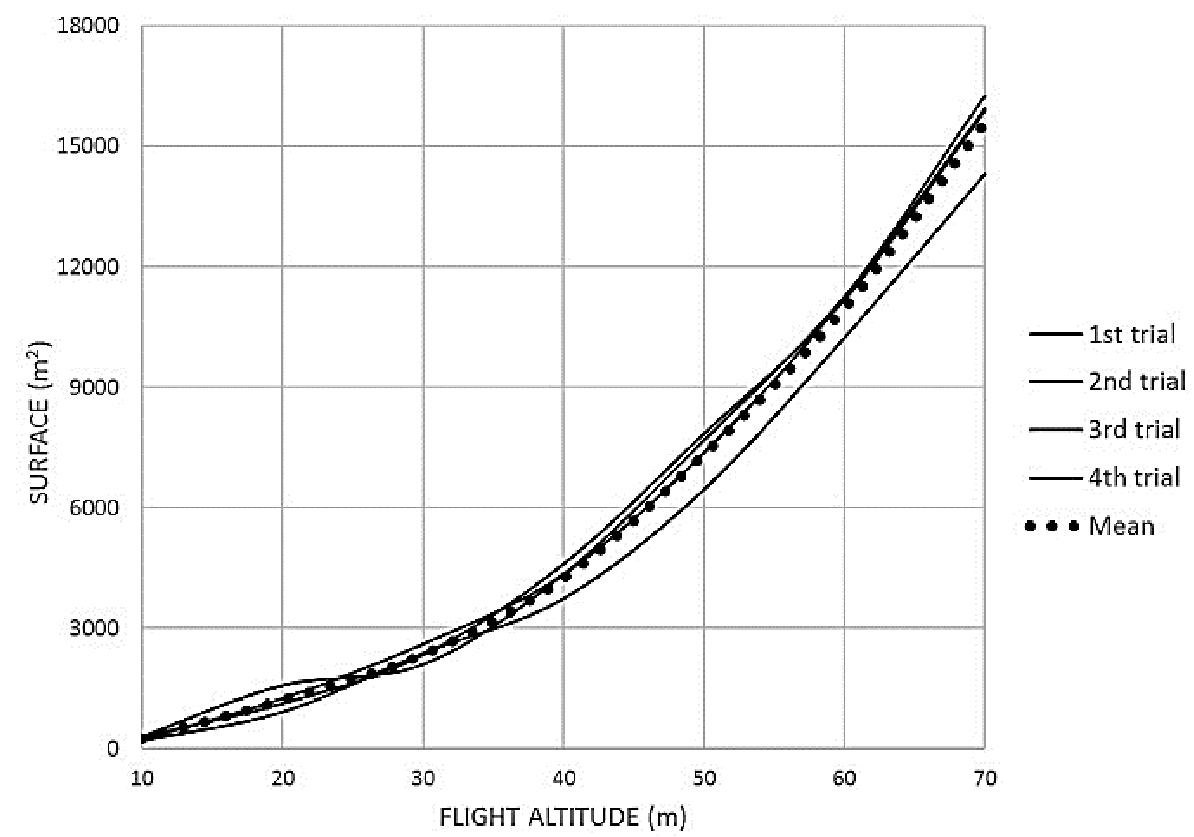

Fig. 5. Breadth of ground recovery surfaces with CG02+ camera from different flight altitude

Furthermore, the videos taken fromthe R.P.A.S. allowed us to effectively locate the animals.

With one flight above the entire study area we could locate 15 Roe deer: none of these showed any reaction to the drone flyover as they continued their feeding activities, even reducing the flight height until $20 \mathrm{~m}$. Figure 7 clearly shows how a Roe deer is identifiable even from higher altitudes. However, these observations depend on the type of the aircraft (fixed or multi-engine wing), the number and the technical characteristics of engines, the type of propellers installed (due to the different quality of sound emissions) and the flight conduct.

Further tests will be needed to define more precisely the technical features of R.P.A.S. applications, but the first results have shown the suitability of the R.P.A.S. for the purpose.

The summary Table 2 shows some aspects related to the advantages and limitations of the use of R.P.A.S. and of the traditional survey from vantage points that emerged during the experimentation. 

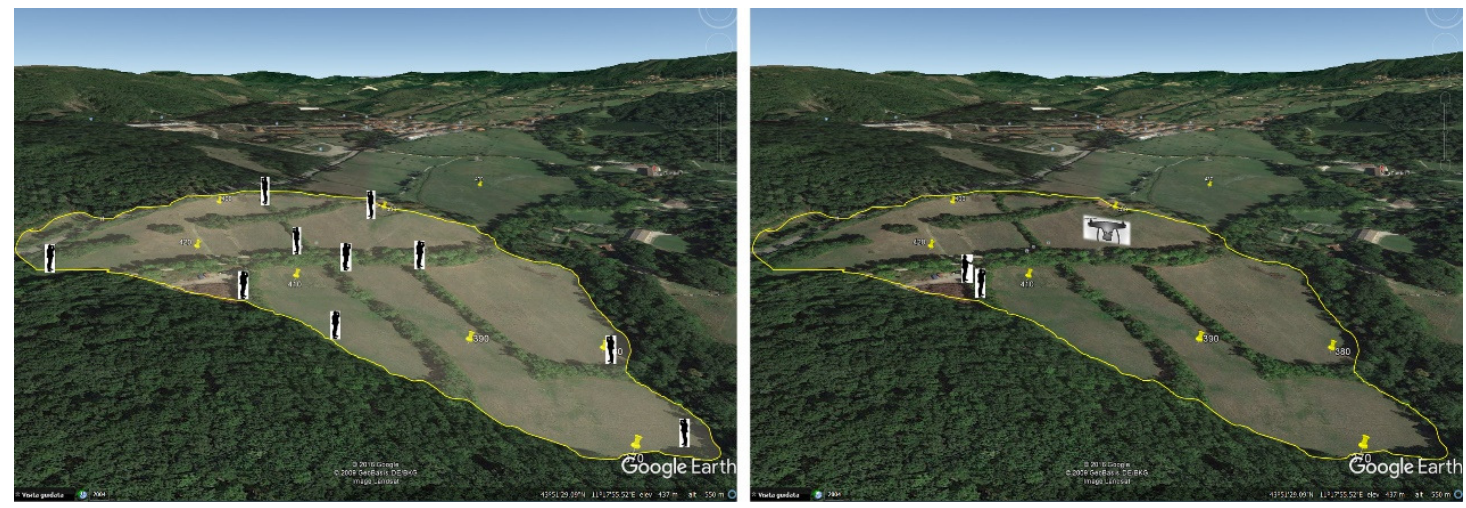

Fig. 6. Comparison between number of operators necessary for monitoring carried out with R.P.A.S. and traditional monitoring carried out from the ground

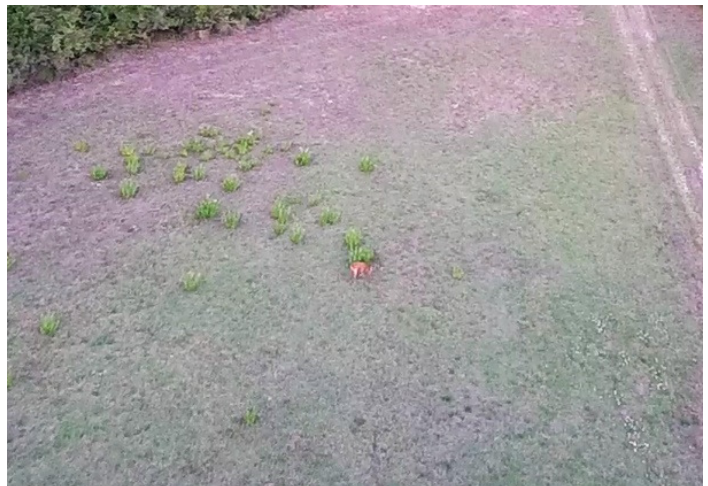

Fig. 7. Detail of image taken from video showing Roe deer feeding, completely unaware of presence of R.P.A.S. at about $40 \mathrm{~m}$ from the ground

Table 2

Comparative report on some aspects concerning censuses by R.P.A.S. and vantage points

\begin{tabular}{|c|c|c|c|}
\hline \multicolumn{2}{|c|}{ R.P.A.S. survey } & \multicolumn{2}{|c|}{ Vantage points survey } \\
\hline PROS & CONS & PROS & CONS \\
\hline Wide shooting area & $\begin{array}{l}\text { Potential disturb using } \\
\text { inappropriate aircraft }\end{array}$ & $\begin{array}{l}\text { Low disturbance by } \\
\text { experienced operators }\end{array}$ & Low observable area \\
\hline $\begin{array}{c}\text { Ability to overcome } \\
\text { natural obstacles }\end{array}$ & $\begin{array}{l}\text { Licenserequirement } \\
\text { for the pilot }\end{array}$ & $\begin{array}{c}\text { No specific titles } \\
\text { necessary }\end{array}$ & $\begin{array}{c}\text { Limited visibility due } \\
\text { to natural obstacles }\end{array}$ \\
\hline $\begin{array}{l}\text { Possible use for night } \\
\text { surveys (w. thermal } \\
\text { camera) }\end{array}$ & $\begin{array}{l}\text { Difficulty in detecting } \\
\text { population structure }\end{array}$ & $\begin{array}{c}\text { Possibility of } \\
\text { surveying the } \\
\text { population structure }\end{array}$ & $\begin{array}{l}\text { Difficult use for night } \\
\text { monitoring }\end{array}$ \\
\hline $\begin{array}{l}\text { Low noise using } \\
\text { appropriate aircraft }\end{array}$ & $\begin{array}{l}\text { Operations influenced } \\
\text { by weather conditions }\end{array}$ & $\begin{array}{l}\text { Low influence of the } \\
\text { weather conditions }\end{array}$ & $\begin{array}{c}\text { Possible disturbance } \\
\text { due to inexperienced } \\
\text { detectors }\end{array}$ \\
\hline $\begin{array}{c}\text { Low number of } \\
\text { operators }\end{array}$ & - & - & $\begin{array}{l}\text { High number of } \\
\text { operators }\end{array}$ \\
\hline Low operational time & - & - & High operational time \\
\hline $\begin{array}{l}\text { Uniformity of the data } \\
\text { collected }\end{array}$ & - & - & $\begin{array}{c}\text { Heterogeneity of the } \\
\text { data collected }\end{array}$ \\
\hline Objectivity of results & - & - & Subjectivity of results \\
\hline $\begin{array}{l}\text { Reduction of double } \\
\text { counting }\end{array}$ & - & - & $\begin{array}{c}\text { Possibility of double } \\
\text { counting }\end{array}$ \\
\hline $\begin{array}{l}\text { Easy repetition of the } \\
\text { census }\end{array}$ & - & - & $\begin{array}{l}\text { Difficult repetition of } \\
\text { the census }\end{array}$ \\
\hline $\begin{array}{l}\text { Possibileto program a } \\
\text { flight mission }\end{array}$ & - & - & \\
\hline
\end{tabular}


The analysis of the images taken with the thermal camera showed that is possible to locate animals even at a considerable distance and distinguish the species, at least for larger ones. Furthermore, it was possible to detect the presence of animals behind not too dense obstacles (Fig. 8, Fig. 9).

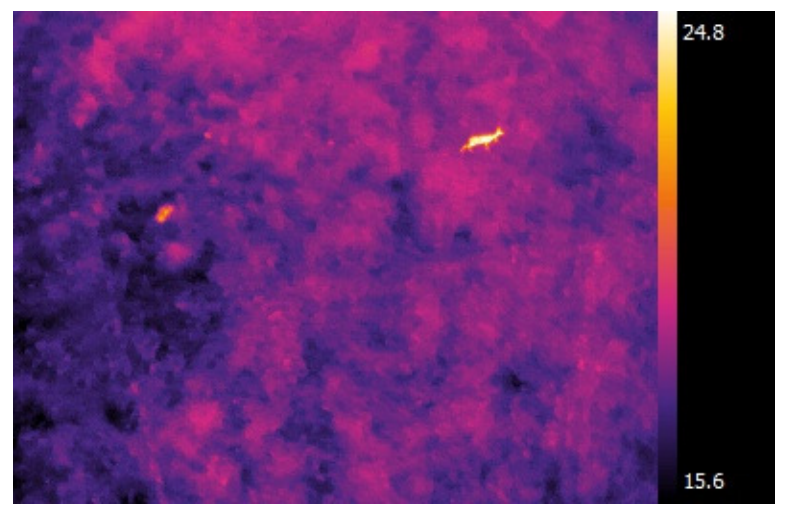

Fig. 8.Thermal camera video frame showing Roe deer, video taken in July at 12:00 P.M. from $40 \mathrm{~m}$ high

It is to be pointed out that, during day flights in summer with thermal camera, the identification of animal shapes is difficult because the temperatures of animals' body and the ground are very similar.Therefore, for a better animal identification the videos are to be taken at night with lower ground temperatures. For this purpose, experimental flights were carried out in July from 7:00P.M. to 12:00P.M. using a caged rabbit as a target (Fig. 10).

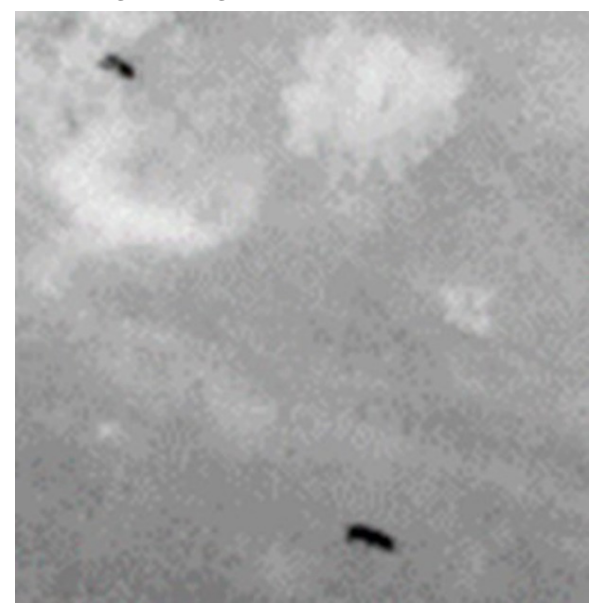

Fig. 9. Grazing Wild boars taken from thermal camera installed on R.P.A.S.

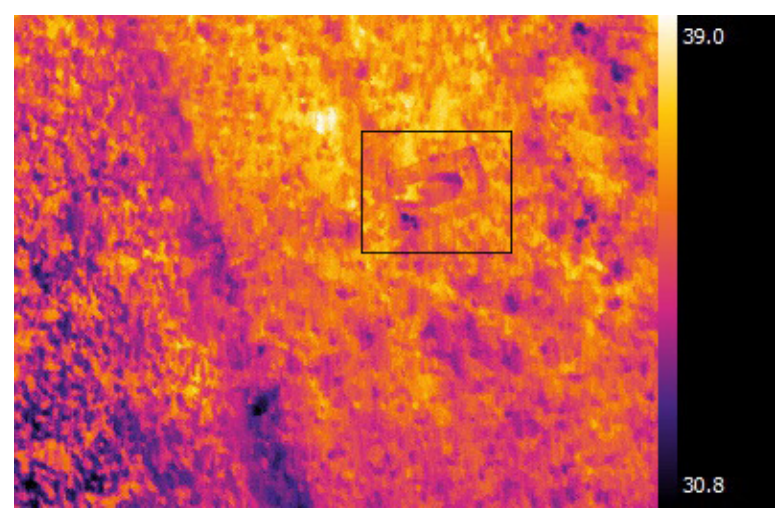

Fig. 10. Thermal camera video frame showing caged Rabbit. Video taken in July at 7:00 P.M. from $10 \mathrm{~m}$ high. Identification of animals is not easy when temperatures of the ground and of the animals' body are similar 


\section{Conclusions}

The purpose of this work was to verify the reactions ofRoe deer and Wild boar to R.P.A.S. flyover and specifically to evaluate the presence or absence of disturb.

Considering the positive results of the tests, it is possible to conclude that the integration of traditional surveys from vantage points with aerial surveys could contribute to rationalize the census. In particular, the use of R.P.A.S. could help to better define the quantitative parameters and the distribution of animal populations. The usefulness of these tools is not to be underestimated for other applications in wildlife monitoring, such as detailed studies of feeding behaviour of animals in agricultural crops orpotential applications tocontrol structures for protection of crops such as electric fences, etc. This is in particular for species that show nocturnal and dusk mobility. The use of the thermal camera installed on R.P.A.S. for monitoring species with high night mobility as Wild boar seems to be useful for the detection. The methodology could also be particularly useful in detecting the presence of ungulates in high density and size crops such as corn, high-grade cereals, etc.

\section{References}

[1] Acevedo Pelayo F., Ruiz-Fons J., Vicente A.R., Reyes-García Alzaga V., Gortázar C. Estimating red deer abundance in a wide range of management situations in Mediterranean habitats. Journal of Zoology, vol. 276(1), 2008, pp. 37-47.

[2] Ponzetta M.P., Sorbetti Guerri F., Banti P., Nuti S. Gli incidenti stradali causati dalla fauna selvatica in Toscana. Analisi del fenomeno nel periodo 2001- 2008. Regione Toscana, 2009, pp. 1-88.

[3] Apollonio M., Andersen R., Putman R. European Ungulates and their management in the 21th century. Cambridge University Press, 2010, pp. 1-578.

[4] Putman R., Apollonio M., Andersen R. Ungulate management in Europe: problems and practice. Cambridge University Press,2011, pp. 1-408.

[5] Sorbetti Guerri F., Bartolozzi S., Racanelli V. Sorbetti Guerri E. Opportunities and limitations using Remotely Piloted Aircraft Systems (R.P.A.S.) for the study of wild ungulates: a first experimental approach for estimating Roe deer (Capreolus capreolus) populations. III Congresso Nazionale Fauna Problematica. Cesena, 2016, pp. 49-50.

[6] Thompson W., White G.C., Gowan C. Monitoring vertebrate population. Academic Press, San Diego,1998, pp. 1-365.

[7] Franzetti B., Focardi S. La stima di popolazione di ungulati mediante distance sampling e termocamera a infrarossi. Ministero delle Politiche Agricole, Alimentari. Italia, 2006, pp. 1-86. 